\title{
Evaluation of the analgesic effect of Umbelliprenin and Umbelliprenin-morphine co-administration on the acute, chronic and neuropathic pain
}

\author{
Mahmoud Hashemzaei', Mohammad Amin SadeghiBonjar' ${ }^{1}$ Kaveh Tabrizian ${ }^{1,2}$, Mehrdad Iranshahi $^{3}$, \\ Milad Iranshahy ${ }^{3}$, Ramin Rezaee ${ }^{4}$
}

1Department of Pharmacology and Toxicology, Faculty of Pharmacy, Zabol University of Medical Sciences, Zabol, Iran

${ }^{2}$ Medicinal Plants Research Center, Zabol University of Medical Sciences, Zabol, Iran

${ }^{3}$ Department of pharmacognosy, Faculty of Pharmacy, Mashhad University of Medical Sciences, Mashhad, Iran

${ }^{4}$ Department of Molecular Sciences, School of Medicine, North Khorasan University of Medical Sciences, Bojnurd, Iran

\begin{abstract}
Background and purpose: Neuropathic Pain (NP) is a complex and chronic pain which is accompanied by nerve injury. Umbelliprenin (UMB) is a naturally occurring prenylatedcoumarin with anticancer, antioxidant, anti-inflammatory, antibacterial and antileishmanial activities. This study aimed to investigate the antinociceptive effects of UMB on acute, chronic and neuropathic pain and its combination therapy with morphine on the neuropathic pain. Methods: Albino mice weighing $20-25 \mathrm{~g}$ were randomly divided into 13 groups $(n=7)$, subjected to hot plate with groups including morphine $1 \mathrm{mg}+$ UMB $(0.01 \mu \mathrm{M} / \mathrm{kg})$, morphine $(1 \mathrm{mg} / \mathrm{kg}$, i.p.), UMB $(0.01 \mathrm{mM} / \mathrm{kg})$, Imipramin $40 \mathrm{mg} / \mathrm{kg}$ and NS (normal saline) $(0.9 \%)$ as vehicle), formalin test with groups including (NS, Imipramine (40 $\mathrm{mg} / \mathrm{kg}$, i.p.), morphine $(9 \mathrm{mg} / \mathrm{kg}$, i.p.) and UMB $(0.01 \mu \mathrm{M} / \mathrm{kg}))$ and morphine tests with groups including (NS $(0.9 \%)$, imipramine $(40 \mathrm{mg} / \mathrm{kg}$, i.p.), morphine $(1 \mathrm{mg} / \mathrm{kg}$, i.p. $)+U M B(0.01 \mathrm{mM} / \mathrm{kg})$ and morphine $(1 \mathrm{mg} / \mathrm{kg}$, i.p.). The acute and neuropathic pain were evaluated using hot-plate and formalin and morphine tests. Results: Administration of UMB single dose $(0.01 \mathrm{mM})$ reduced NP significantly $(p<0.05)$ compared to the negative control and didn't change acute pain against Diclofenac. Antinociceptive effects of UMB were comparable to Imipramine as a standard positive control. UMB potentiated morphine $1 \mathrm{mg} / \mathrm{kg}$ response on NP. Conclusion: This research indicates that UMB alone reduces NP and its combination with morphine potentiates morphine effects. Therefore, UMB-morphine co-administration is proposed to be used instead of conventional treatment.
\end{abstract}

Key words: Umbelliprenin, Neuropathic Pain, Morphine, Sciatic Nerve Ligation.

\section{INTRODUCTION}

Neuropathic Pain (NP) is caused by cancer, diabetes mellitus, Parkinson's disease, Alzheimer's disease. About more than $3-4.5 \%$ of global population is suffering from NP. Classical analgesics such as anticonvulsants, tricyclic antidepressants, local anesthetics, opioids analgesic have inconsistent benefit or adverse effects. About $10-30 \%$ of patients suffering from syndromes of NP are drug resistant. ${ }^{1}$ There is remarkable need for novel analgesic being more effective or safer.

$\mathrm{UMB}$, a prenylated coumarin, is related to naturally occurring compounds, which are widely distributed in Ferula plant species such as Citrus limon. ${ }^{2-4}$ It has been also found in celery, Angelica archangelica, Coriandrum sativum. They are belonged to a very large class of sesquiterpene which possess anticarcinogenic, free radical scavenging, anti-inflammatory, antileishmanial properties and were shown to be able to inhibit red pigment production in Serratia marcescens, decrease matrix metalloprotease (MMP) activity, and inhibit lipoxygenase and acetyl cholinesterase.

Anti-inflammatory and antinociceptive effects of UMB analogues have been studied. ${ }^{5,6}$ UMB inhibits iNOS mRNA and COX-2 mRNA expression which seem to be related to its anti-inflammatory effects
Submission Date :28/07/2014 Revision Date : :26/11/2014 Accepted Date : :23/12/2014

DOI: 10.5530/ijper.49.2.7

Correspondence Address Dr.Mahmoud Hashemzaei Department of Pharmacology and Toxicology, Faculty of Pharmacy, Zabol University of Medical Sciences, Zabol, Iran Phone: +985422253527 Fax: +985422253528 E-mail:mahmoodnima2000@yahoo.com

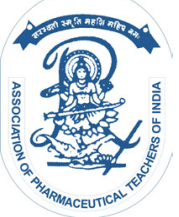

www.ijper.org 
in human lymphocytes and reduces transcription of related proteins. ${ }^{6,-10}$ Furthermore, coumarins have antinociceptive effect via opiodic pathway. ${ }^{2,11}$ The roots of Ferula persica possessing UMB, are used for the treatment of diabetes in folk medicine. ${ }^{12} \mathrm{UMB}$ has strong lipoxygenase inhibitory properties and also has shown antiinflammatory effect in the carrageen an hind paw edema model in mice. ${ }^{5}$

In this study, we attempted to determine the acute and chronic antinociceptive effect of UMB alone, and in combination with morphine to investigate whether it can potentiate morphine anti-neuropathic pain.

\section{METHODS}

\section{Animals and surgery}

Male Albino mice produced from Faculty of Pharmacy of Zabol University of Medical Sciences weighing 20-25 g were randomly divided into 13 groups $(n=7)$, subjected to hot plate test including morphine $1 \mathrm{mg}+$ UMB $(0.01 \mu \mathrm{M} / \mathrm{kg})$, morphine $(1 \mathrm{mg} / \mathrm{kg}$, i.p.), UMB (0.01 mM/kg), Imipramin $40 \mathrm{mg} / \mathrm{kg}$ and NS (normal saline) $(0.9 \%)$ as vehicle), formalin test including NS, Imipramine (40 mg/kg, i.p.), morphine (9 $\mathrm{mg} / \mathrm{kg}$, i.p.) and $\mathrm{UMB}(0.01 \mu \mathrm{M} / \mathrm{kg})$ and morphine tests with 4 groups including NS $(0.9 \%)$, imipramine $(40 \mathrm{mg} / \mathrm{kg}$, i.p.), morphine (1 mg/kg, i.p.)+UMB (0.01 mM/kg) and morphine $(1 \mathrm{mg} / \mathrm{kg}$, i.p.).The animals were kept under constant temperature $\left(22-25^{\circ} \mathrm{C}\right), 12$ hour light/ dark cycle and had free access to food and water. All procedures were in accordance with the guidelines from the declaration of Helsinki principles in the study of experimental animals.

\section{Surgery}

The animals were anesthetized by ketamine (40 mg/ $\mathrm{kg}$, i.p.) (Merck; Germany) and xylazine $(10 \mathrm{mg} / \mathrm{kg}$, i.p.) (Merck; Germany).Sciatic nerve was ligated in the hind limb using a piece of copper wire. ${ }^{13}$

\section{Chemicals}

UMB was synthesized via the reaction of 7-hydroxycoumarin $(1 \mathrm{~mol} / \mathrm{l})$ and trans-trans-farnesyl bromide $(1.5 \mathrm{~mol} / \mathrm{l})$ in acetone at room temperature. ${ }^{11}$ The reaction was accomplished in the presence of DBU (1, 8-diazabicyclo [5.4.0] undec-7-ene) (2M). $24 \mathrm{~h}$ later, the mixture was concentrated under reduced pressure and was purified by column chromatography (petroleum ether/ethyl acetate 9: $1 \mathrm{v} / \mathrm{v}$ ) as white crystals. ${ }^{11}$

\section{Analgesic measurement}

Hot-plate test
The Hot-plate test was performed to determine the effect of UMB on NP, ${ }^{17}$ with minor modifications. The animals were placed on a circular surface (diameter $19 \mathrm{~cm}$ ) maintained at $55 \pm 0.2^{\circ} \mathrm{C}$ and surrounded by a Plexiglas wall $(12 \mathrm{~cm}$ high). The apparatus (Harvard; England) was equipped with a timer and a thermo coupler to maintain a constant temperature. Licking the forepaws, lifting hind paws or jumping from the surface was considered as the end point of response latencies. ${ }^{18}$ 45 seconds were indicated as cut-off time. 2 weeks after nerve ligation, pain intensity was measured.

\section{Formalin test}

The formalin test was performed to determine acute and chronic pain of UMB single dose $(0.01 \mathrm{mM} / \mathrm{kg}$, i.p.). The mice were considered to evaluate neuropathic pain at different times after formalin injection $(0,30,60$, 90 and $120 \mathrm{~min})$. All mice received an intraplantar injection of formalin ( $1 \%$ in saline) in the left hind paw. The duration of paw flinches, licking, and biting, 0-5 min after injection of formalin (first phase) and between 20 and $40 \mathrm{~min}$ (second phase) was recorded. ${ }^{14}$

\section{Morphine (1 mg/kg) UMB (0.01 mM/kg)}

This test was performed to elucidate whether UMB is able to change morphine ( $1 \mathrm{mg} / \mathrm{kg}$, i.p.) effect on NP or not. The mice were randomly assigned in groups of NS $(0.9 \%)$, imipramine $(40 \mathrm{mg} / \mathrm{kg}$, i.p.), morphine $(1 \mathrm{mg} /$ $\mathrm{kg}$, i.p. $)+\mathrm{UMB}(0.01 \mathrm{mM} / \mathrm{kg})$ and morphine $(1 \mathrm{mg} / \mathrm{kg}$, i.p.) to evaluate neuropathic pain at different times after formalin injection $(0,30,60,90$ and $120 \mathrm{~min})$.

\section{Statistical analysis}

Data was analyzed using Graph Pad Prism 5.00. Oneway ANOVA followed by Newman-Keuls test to situations the potential differences was done. We used unpaired $\mathrm{T}$ test for comparison between control animals and the sciatic nerve ligated group. Statistically significant differences considered as $\mathrm{p}<0.05$. Data is represented as mean \pm SEM.

\section{RESULTS}

\section{Effects of UMB single dose on neuropathic pain 14 days after sciatic nerve ligation using hot plate test at 0, 30, 60, 90 and 120 min.}

There were significant differences between UMB (0.01 $\mathrm{mM} / \mathrm{kg})+$ morphine $(1 \mathrm{mg} / \mathrm{kg})$, Imipramine $(40 \mathrm{mg} /$ $\mathrm{kg}), \mathrm{UMB}(0.01 \mathrm{mM} / \mathrm{kg})$ and morphine $(1 \mathrm{mg} / \mathrm{kg})$, at 0 min (Figure 1: A). 30 min later, there were significant differences between all groups and the control group and also there was significant difference between morphine $1 \mathrm{mg} / \mathrm{kg}$ and $\mathrm{UMB}+$ morphine $1 \mathrm{mg} / \mathrm{kg}(\mathrm{p}<0.05)$ (Figure 1: B). After 60, 90 and $120 \mathrm{~min}$, there were significant 

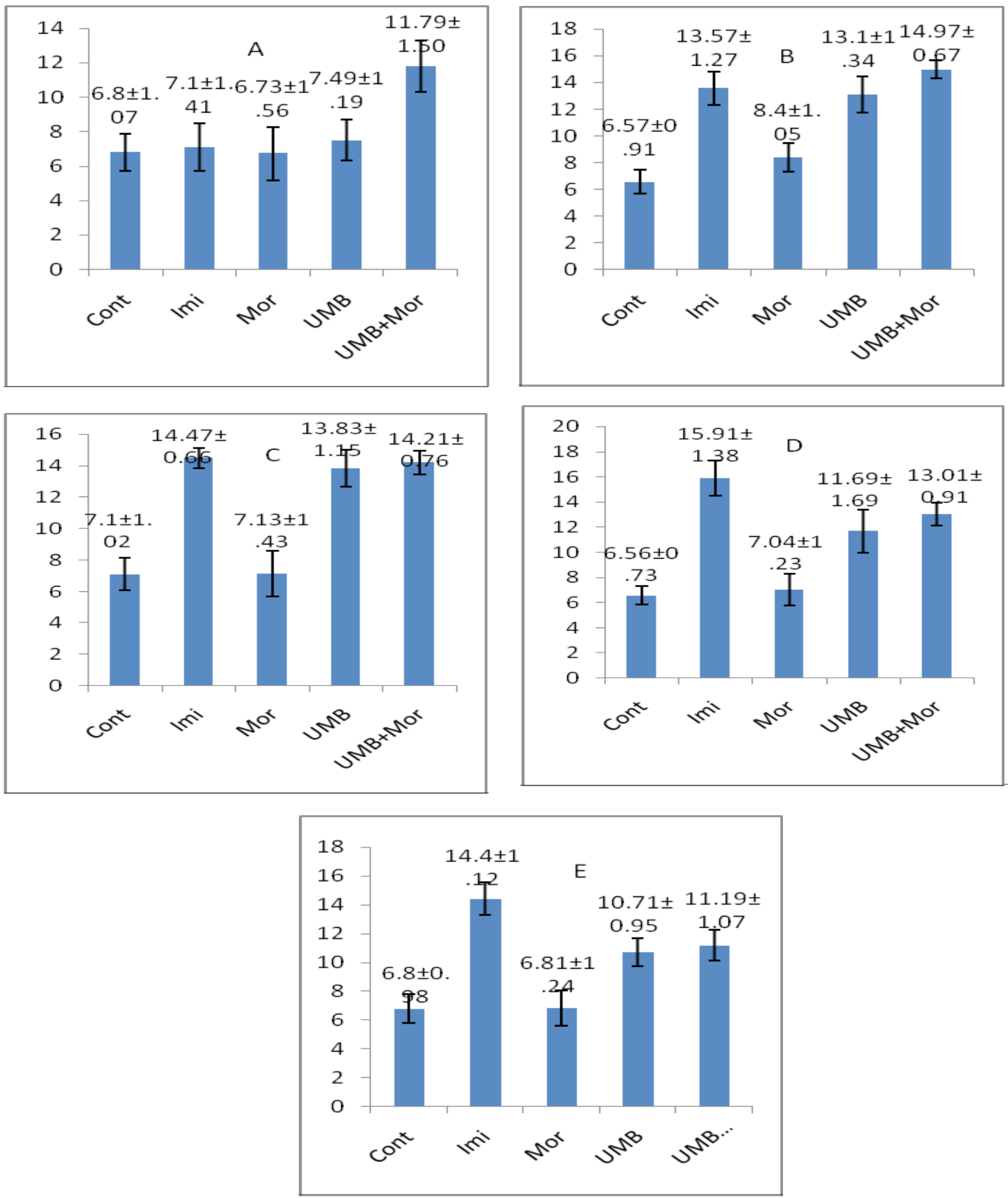

Figure 2: Effects of single dose of UMB on licking and latency response on the acute (A and $B)$ and chronic (C and D) phase of the formalin test.

Data is presented as Mean \pm SEM.

differences between Imipramine, UMB, and morphine 1 $\mathrm{mg} / \mathrm{kg}+\mathrm{UMB}(0.01 \mathrm{mM} / \mathrm{kg})$ and morphine $1 \mathrm{mg} / \mathrm{kg}$ and NS groups $(p<0.001)$ (Figure 1: C, D and E).

Effects of single dose of UMB on licking and latency response on the acute phase of the formalin test.

There were significant differences between UMB $(p<0.05)$, morphine $(p<0.001)$ and Diclofenac $(p<0.01)$ and the control group (Figure 2: A \& B). 

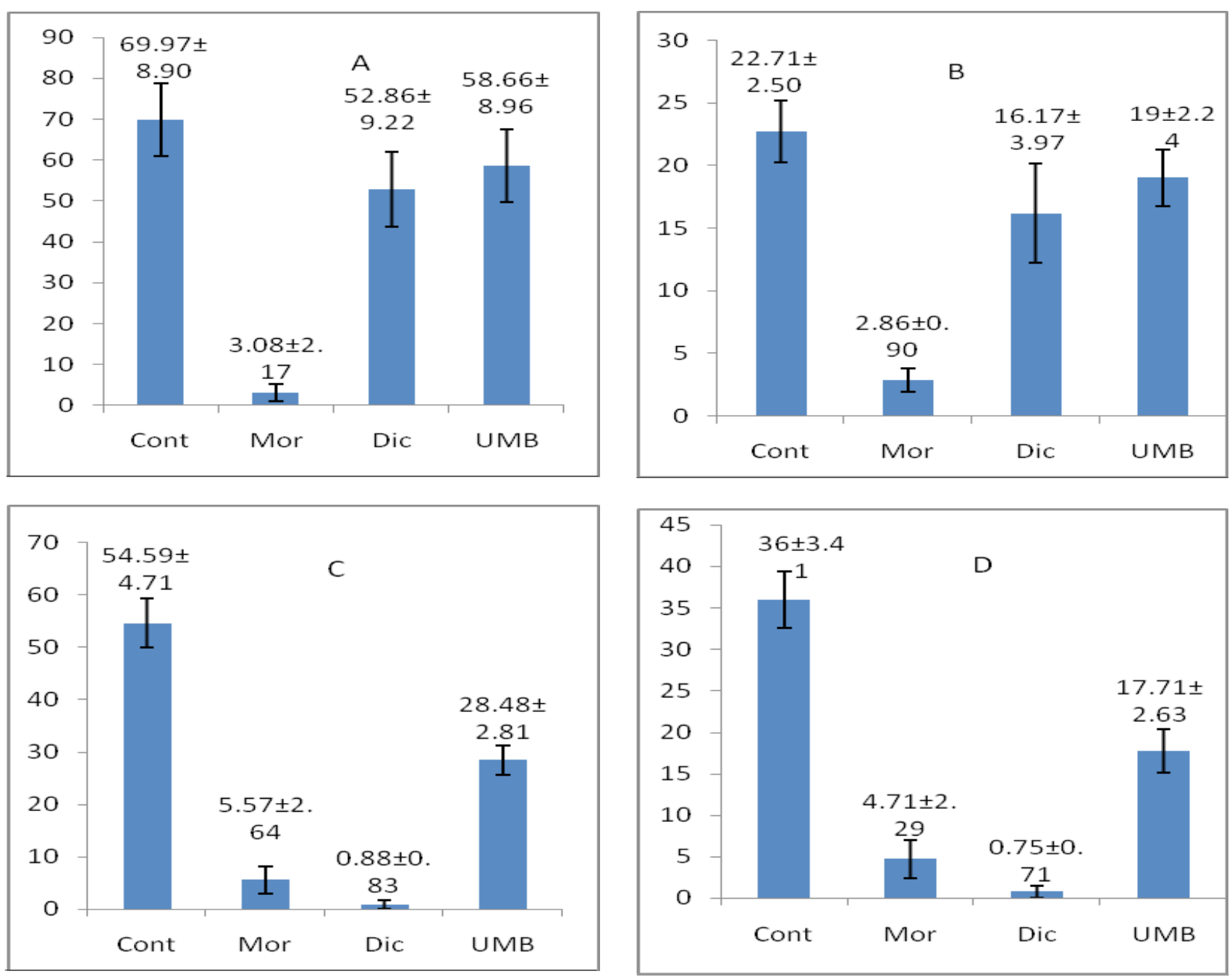

Figure 2: Effects of single dose of UMB on licking and latency response on the acute (A and $B)$ and chronic (C and D) phase of the formalin test.

Data is presented as Mean \pm SEM.

Effects of UMB single dose on licking and latency response in the chronic phase in the formalin test.

There were significant differences between UMB, morphine and Diclofenac and the control group $(p<0.001)$ (Figure 2: C \& D).

\section{DISCUSSION}

The results indicated that UMB reduced chronic and acute pain. Moreover, NP due to sciatic nerve ligation in mice model was alleviated by UMB $(0.01 \mathrm{mM} / \mathrm{kg}$ i.p. $)$ $\mathrm{UMB}(0.01 \mathrm{mM} / \mathrm{kg}$ i.p. $)$ in combination with morphine $(1 \mathrm{mg} / \mathrm{kg})$ could potentiate its antinociceptive effect. This was the first study on the effect of UMB on the antihyperalgesia, antinociceptive, anti-neuropathic pain and its combination with morphine.

Several studies showed that coumarin has antinociceptive and antihyperalgesia effects ${ }^{5,6,15,16} \mathrm{UMB}$ is chemically belonged to 7-hydroxycoumarins (7-HC)which have in vivo and in vitro anti-inflammatory analgesic and anti- pyretic effects, seems to be related to their ability in COX-2 inhibition. ${ }^{16} \mathrm{UMB}$ has surprisinginhibitory activity on soybean lipooxygenase enzyme, the key enzyme in inflammatory process, with $\mathrm{IC}_{50}$ value of $0.0725 \mu \mathrm{M}$, compared tocaffeic acid, with $\mathrm{IC}_{50}$ value of $600 \mu \mathrm{M} .^{5}$ It has been shown that $0.01 \mathrm{mM}$ i.p.adminstartion of $\mathrm{UMB}$ can significantly ameliorate inflammation, which is comparable to Indomethacin. ${ }^{5}$

Following the formalin injection, hyperalgesia is divided into acute (the first 3-5 min) and chronic phase (15-20 min after formalin injection). UMB subsided both acute and chronic pain significantly.Nitric Oxide (NO) is one of the mostdetrimental especially chronic pain. Formalin rises nitrite and nitrate lavels in plasma viaactivation of iNOS. In addition, NO can activate lipoxigenas and cycloxigenase enzymes activity and consequently increases inflammatiory and pain transduction via releasing substance P, PG and luckutereins. Induction of pain in formalin test is facilitated by i.p.injection of the substances that increase NO level. Furthermore, 
adminstration of iNOS inhibitors (p.o.,i.p. or intrathecaal) can alleviate nociception especiallyin the second phase of formalin test and it is consistent with our study. Lipoxigenase metabolites increase senstivity to pain in the second phase of formalin test by increasing production of hydroperoxyeicosatetraenoic acid $\left(\mathrm{HPETE}_{\mathrm{s}}\right)$ from arachidonic acid by 5,12, and 15 lipoxygenase. HPETE $_{S}$, immediately after production, are converted to leukotrienes which the process can be inhibited by UMB.${ }^{17}$ Using up to $20 \mu \mathrm{g} / \mathrm{ml}$ of UMB, decreased the production of $\mathrm{NO}$ and expression of inducible nitric oxide synthase (iNOS). ${ }^{6}$

NP is a relatively common pain that is associated with nervous system lesions or dysfunction. ${ }^{18}$ The results showed that UMB could alleviate NP following sciatic nerve ligation. It was shown that iNOS and NO are involved in inflammation, neurodegeneration, and NP and one of underlying mechanism of UMB is iNOS inhibitory effects. ${ }^{19-21}$

UMB $(0.01 \mathrm{mM})$ with morphine $(1 \mathrm{mg} / \mathrm{kg})$ potentiated morphine antinociceptive effects. UMB shows its antinociceptive effcts partly via $\mu$ receptors stimulation.

\section{REFERENCES}

1. Blackburn-Munro G, Erichsen HK. Antiepileptics and the treatment of neuropathic pain: evidence from animal models. Curr Pharm Des. 2005; 11(23): 2961-76.

2. Iranshahi M, Shahverdi AR, Mirjani R, Amin G, Shafiee A. Umbelliprenin from Ferula persica roots inhibits the red pigment production in Serratia marcescens. Z Naturforsch [C] 2004; 59(7/8): 506-8.

3. Shahverdi AR, Saadat F, Khorramizade MR, Iranshahi M, Khoshayand MR. Two matrix metalloproteinases inhibitors from Ferula persica var. persica. Phytomedicine 2006; 13(9): 712-7.

4. Iranshahi M, Arfa P, Ramezani M, Jaafari MR, Sadeghian H, Bassarello $C$, et al. Sesquiterpene coumarins from Ferula szowitsiana and in vitro antileishmanial activity of 7-prenyloxycoumarins against promastigotes. Phytochemistry 2007; 68(4): 554-61.

5. Iranshahi M, Askari M, Sahebkar A, Adjipavlou-Litina D. Evaluation of antioxidant, anti-inflammatory and lipoxygenase inhibitory activities of the prenylated coumarin umbelliprenin. DARU J Pharm Sci. 2009; 17(2): 99-103.

6. Iranshahi M, Mahmoudi M, Zamanai Taghizadeh Rabe SH, Siadat Z. Antiinflammatory effect of Umbelliprenin from Ferula szowitsiana mediated by the inhibition of nitric oxide production by inflammatory macrophages. Clin Biochem. 2011; 44(13): 37.

7. Hong $\mathrm{CH}$, Hur SK, Oh OJ, Kim SS, Nam K, Lee SK. Evaluation of natural products on inhibition of inducible cyclooxygenase (COX-2) and nitric oxide synthase (iNOS) in cultured mouse macrophage cells. J Ethnopharmacol. 2002; 83(1): 153-9.

8. Dray A. Inflammatory mediators of pain. Brit J Anaesth. 1995; 75(2): 125-31.

9. Moalem G, Tracey DJ. Immune and inflammatory mechanisms in neuropathic pain. Brain Res Rev. 2006; 51(2): 240-64.

10. Le Bars D, Adam F. Nociceptors and mediators in acute inflammatory pain. Ann francaises d'anesthesie et de reanimation 2002; 21(4): 315-35.

11. Askari M, Sahebkar A, Iranshahi M. Synthesis and Purification of 7-Prenyloxycoumarins and Herniarin as Bioactive Natural Coumarins. Iranian J Basic Med Sci. 2009; 12(2): 63-9.

12. Afifi FU, Abu-Irmaileh B. Herbal medicine in Jordan with special emphasis on less commonly used medicinal herbs. J Ethnopharmacol. 2000; 72(1): 101-10.
It was elucidated that coumarins pose their effects via stimulation of opioid receptors. ${ }^{15,22}$ Coumarins have inhibitory effects on $\mathrm{NO}$ and $\beta$-Ep levels in brain. It could be concluded that its potentiating effect on morphine is via direct activation of $\mu$ receptors. ${ }^{15,22}$

Matrix Metalloproteinase Proteins (MMPs) are critical enzymes in tumor, neovascularization and inflammation. Another hypothetical mechanism of UMB is reduction of pro-inflammatory proteins and decreasing of MMPs. ${ }^{3}$ Each component with MMP inhibitory effect such as Diclofenac sodium poses anticancer due to anti-inflammatory effect. ${ }^{3}$ Many other substances that can decrease MMPs in cells also ameliorate inflammations that are in accordance with our findings. 3,23

\section{CONCLUSION}

Taken together, UMB has strong antihyperalgesia, antiinflammatory effect especially in the late phase of formalin test. Moreover, it can potentiate morphine $(1 \mathrm{mg} /$ $\mathrm{kg}$ ) antinociceptive effects in combination with a single dose of UMB (0.01 mM i.p.).
13. Malmberg AB, Basbaum Al. Partial sciatic nerve injury in the mouse as a model of neuropathic pain: behavioral and neuroanatomical correlates. Pain 1998; 76(1): 215-22

14. Hunskaar S, Hole K. The formalin test in mice: Dissociation between inflammatory and non-inflammatory pain. Pain 1987; 30(1): 103-14.

15. Leal LKAM, Ferreira AAG, Bezerra GA, Matos FJA, Viana GSB. Antinociceptive, anti-inflammatory and bronchodilator activities of Brazilian medicinal plants containing coumarin: a comparative study. J Ethnopharmacol. 2000; 70(2): 151-9.

16. Barros TA, de Freitas LA, Filho JM, Nunes XP, Giulietti AM, de Souza GE, et al. Antinociceptive and anti-inflammatory properties of 7-hydroxycoumarin in experimental animal models: potential therapeutic for the control of inflammatory chronic pain. J Pharm Pharmacol. 2010; 62(2): 205-13.

17. Singh VP, Patil CS, Kumar M, Kulkarni SK. Effect of 5-lipoxygenase inhibitor against lipopolysaccharide-induced hypothermia in mice. Indian J Exp Biol. 2005; 43(12): 1150-5.

18. Vranken $\mathrm{JH}$. Mechanisms and treatment of neuropathic pain. Cent Nerv Sys Agents Med Chem. 2009; 9(1): 71-8.

19. Tal M. A novel antioxidant alleviates heat hyperalgesia in rats with an experimental painful peripheral neuropathy. Neuroreport 1996; 7(8): 1382-4.

20. Karimi G, Tabrizian K, Rezaee R. Evaluation of the analgesic effect of Dextromethorphan and its interaction with nitric oxide on sciatic nerve ligated rats. J Acupunct Meridian Stud. 2010; 3(1): 38-42.

21. Kohno S, Murata T, Sugiura A, Ito C, Iranshahi M, Hikita K, Kaneda N. Methyl galbanate, a novel inhibitor of nitric oxide production in mouse macrophage RAW264.7 cells. J Nat Med. 2011; 65(2): 353-9.

22. Park SH, Sim YB, Kim SM, Lee JK, Lim SS, Kim JK, et al. Antinociception effect and mechanism of Ruta graveolens L. in mice. J Korean Soc Applied Biol Chem. 2010; 53(5): 593-7.

23. Saadat F, Zomorodian K, Pezeshki M, Khorramizadeh MR. The potential role of nonsteroidal antiinflammatory drugs (NSAIDS) in chemoprevention of cancer. Pakistan J Med Sci. 2003; 19(1): 13-8. 